\title{
A relação entre a Controladoria e a Administração: Especialização ou Invasão de Área?
}

\author{
Jéssica Santos de ASSUNÇÃO.
}

Faculdades Integradas de Garanhuns (FACIGA)

\section{Aécio Cristóvão Pereira de MELO}

Faculdades Integradas de Garanhuns (FACIGA)

\section{Gabriela Fernanda de Alcântara Valença PAIVA}

Faculdades Integradas de Garanhuns (FACIGA)

\author{
Received 8 Jun. 2018; Accepted 21 Jun. 2018 \\ Evaluation System: Guest Article \\ Editor: Jose Lindenberg Julião Xavier Filho, Dr. \\ ISSN: 2594-8040
}

To cite this paper: Assunção, J. S., Melo, A. C. P., \& Paiva, G. F. A. V. (2018). A relação entre a Controladoria e a Administração: Especialização ou invasão de área? Journal of Perspectives in Management - JPM, 2(1), p. 32-46.

\section{Resumo}

Diante do distanciamento empírico observado entre os administradores e contadores, tem surgido diversas áreas, uma delas é a controladoria. Com base nesta evidência, o objetivo deste estudo é discutir se controladoria figura como uma nova profissão ou um avanço em especialização da Administração e/ou da Contabilidade, tendo por objetivos secundários definir e sumarizar as funções da administração, contabilidade e controladoria. Para isso, realizou-se uma revisão acerca das funções de cada área, tentando entender os limites de cada profissional e quais os elementos essenciais para formação de uma profissão, de acordo com a visão funcionalista da teoria das profissões. Foi montado um corpus, para evidenciar as funções, a partir de artigos científicos publicados no período de 2011 a 2016, nos sites Spell e o Scielo, dissertação, tese e livros. Foi considerado os textos que tratavam das funções da controladoria, de forma empírica e não apenas conceitual. O resultado mostrou que segundo a visão funcionalista da sociologia das profissões, a controladoria não se enquadra ainda como profissão, por ausência de elementos essenciais, tais como: conhecimento estruturado, código de ética e associações profissionais. Visualizou-se também que ela extrapola o limite da contabilidade, e adentra na área da administração, isso acontece pela falta de consenso quanto as suas funções e área de atuação. Neste sentido, este estudo contribui para o entendimento das funções da administração e sua vinculação com saberes emergentes, especificamente controladoria.

Palavras-Chave: Administração; Controladoria; Contabilidade. 


\section{Introdução}

A principal ação do administrador é tomar decisão, como destacam Fayol (2009), Taylor (2008), Maximiano (2008), entre outros, e são decisões que tem por característica o impacto holístico na organização. A importância de tal ação já vem destacada pelo Conselho Nacional de Educação (CNE), quando define que na graduação o administrador deve desenvolver, entre outras, a função de "tomar decisão" (CNE, 2005, p. 2), no entanto, pesquisas recentes mostram que as escolas de administração têm perdido este fio condutor, afastando a formação do real exercício de sua profissão.

Fayol (2009) indica que são funções do administrador planejar, dirigir, organizar e controlar, todas essas envolvendo o processo de tomada de decisão, que é de extrema importância para a obtenção do sucesso, e também para que a empresa consiga ter eficiência e manter-se competitiva no mercado.

A informação é uma ferramenta essencial para a gestão organizacional, pois ela dá condições ao administrador de tomar decisões. Ching, Marques e Prado (2010) afirmam que quanto mais importante for a decisão, maior a necessidade de informação.

Desde os primeiros desenhos das funções do administrador, sobretudo em Fayol (2009), a fonte responsável por gerar informações para orientar as decisões é a contabilidade. Fayol (2009, p.25) comenta que "uma boa contabilidade, simples e clara, que dê ideia exata das condições da empresa, é poderoso meio de direção", tanto que Jiambalvo (2009) define o objetivo da contabilidade como fornecer informações necessárias para o planejamento, o controle e a tomada de decisão, funções características da gestão.

É possível notar por meio de pesquisas, que acontece uma falha na comunicação entre a administração (que toma decisões de âmbito organizacional) e a contabilidade (que fornece informações auxiliando a decisão). E essa falha na comunicação entre os dois campos, tem ocasionado no mercado uma demanda cada vez mais crescente de profissionais que possam mediar tal relação, um deles é o controller.

Borinelli (2006) refere que a controladoria é uma unidade do sistema formal sendo responsável pelo controle do processo de gestão e pela geração e fornecimento de informações de diversas ordens podendo ser: operacional, econômica, financeira e patrimonial. Ainda na visão de Borinelli (2006), ela surgiu das mudanças da contabilidade gerencial, e ajuda a direção e os gestores com informações que auxiliam a traçar as metas a serem seguidas e a tomar decisões baseadas nas informações recebidas, parecendo uma evolução ou mesmo uma especialização da área de contabilidade.

Contudo, entender uma nova profissão como sendo um novo saber emergindo de necessidades práticas merece um estudo mais aprofundado, por isso, nesta pesquisa a questão norteadora é: Como a controladoria se relaciona com a Contabilidade e Administração: Uma nova profissão ou uma especialização?

Com isso torna-se importante discutir quais atividades são expressões de cada saber, para que possa entender os "limites" de atuação para cada "profissional", definindo e sumarizando as funções da administração, contabilidade e controladoria.

\section{Referencial Teórico}

Esta seção apresenta a conceituação de o que vem a ser uma profissão por meio da Sociologia das Profissões, narrando como surge uma profissão. Em seguida, apresenta e debate sobre as principais funções e características da Administração, Contabilidade e Controller.

\subsection{Como se forma uma profissão}

O conceito de profissão surgiu na Idade Média, com as características dos trabalhos artesanais realizados nas guildas, que eram compostas em unidades de produção, de capacitação para o trabalho e de comercialização do produto. Porém, muitas foram as mudanças históricas que aconteceram, e acarretaram mudanças no universo profissional até os dias atuais.

Com o trabalho The Professions em 1933, por Carr-Saunders e Wilson, na Inglaterra, onde buscou levantar os grupos profissionais que poderiam ser classificados em profissão, foi que deu origem a sociologia das profissões, sendo responsável por produzir conhecimento a respeito dessa temática. Segundo Bonelli (1993, p. 32), "a base da classificação era a existência de um corpo organizado que dominasse um conhecimento baseado num sistema de ensino e treinamento, com seleção prévia através de exame, e possuísse códigos 
de ética e de conduta". Esses eram os critérios que foram usados para definir profissão que duram alguns anos.

Por meio da sociologia das profissões, os princípios definidores de uma profissão são: colegialidade, cognitivo e moral. Os quais podem ser entendidos como: "credenciais, conhecimento e código de ética" (Barbosa, 1993, p. 22).

Surgiram algumas correntes teóricas que desenvolveram estudos a respeito das profissões, dentre elas as abordagens de Durkhein, Weber e a visão Marxista.

As profissões em Durkhein apresentavam uma visão funcionalista, para esta corrente, os principais critérios para destacar uma profissão eram os profissionais terem treinamento técnico formal, atuarem na área que forem treinados, ter domínio de racionalidade cognitiva, desenvolver habilidades específicas (Rodrigues, 2002; Pires, 2009).

Segundo Angelin (2010), os funcionalistas destacaram várias características que permitem distinguir uma profissão de uma ocupação. Dentre elas, se tornam proeminentes o domínio de um conjunto de conhecimentos técnico-científicos, código de ética e associações profissionais, que se mostram importantes para o processo de profissionalização. Embora surgissem outras visões e fosse questionado o modelo de visão funcionalista, as características de conhecimentos técnicocientíficos, código de ética e associações profissionais, são citadas em diversas outras visões.

\subsection{Administração: Suas funções características}

Em um mundo cada vez mais competitivo o administrador tem o desafio de ser eficiente e eficaz para que possa assegurar cada vez mais crescimento para a empresa e para o funcionário, conseguindo assim alcançar o resultado para o que ela fosse criada, que é obter resultados (Chiavenato, 2006; Taylor, 2008). Segundo Motta (2003, p. 6), "alguém consegue ser um bom administrador à medida que planeja cuidadosamente todos os seus passos, organiza e coordena as atividades de seus subordinados e comanda e controla o desempenho". Usando desta afirmação que o administrador precisa planejar, organizar, coordenar, comandar e controlar, será feita uma análise que busque resumir tais funções.

A primeira função a ser analisada é a de planejar, e diversas são as nomenclaturas usadas, principalmente conhecidas com planejar e prever, porém o sentido principal é justamente de prepararse para o futuro, traçando as estratégias que consigam obter o melhor aproveitamento de todos os recursos (mão-de-obra, matéria prima, equipamentos, etc.), pois com um bom planejamento é possível evitar falhas, que podem chegar até a comprometer a organização (Chiavenato, 2006; Maximiano, 2008; Fayol, 2009).

$\mathrm{O}$ ato de organizar segundo a definição dos autores é definir como será feito e quem fará, buscando otimizar todos os recursos disponíveis para que se possa alcançar os objetivos traçados (Maximiano, 2008; Fayol, 2009).

Comandar, após planejar, entendido como definir os objetivos a serem alcançados, inicia-se a função de organizar, que é alocar todos/tudo de forma a render mais, em seguida o processo de coordenar, significando administrar e motivar as pessoas para que realizem o esperado (Maximiano, 2008; Fayol, 2009).

Coordenar após as metas definidas e quem vai desempenhar cada atividade é preciso unir todos os processos para que na soma de todos consigam alcançar o objetivo determinado no planejamento. Para que isso aconteça, é necessária atenção para alocar as pessoas nos lugares certos para que possam produzir cada vez mais e da melhor forma (Maximiano, 2008; Fayol, 2009).

A função de controlar é o ato de verificar se as metas estabelecidas estão sendo cumpridas, se não estão, onde está o problema e adequar o processo para os objetivos já definidos no planejamento sejam alcançados (Maximiano, 2008; Fayol, 2009).

Para que os profissionais que trabalham nessa área estejam preparados nas mais diversas situações, é importante que sejam desenvolvidas essas habilidades no período de formação. Na resolução $n^{\circ}$ 4 do Conselho Nacional de Educação (CNE, 2005) em seu artigo $3^{\circ}$, define que no curso de graduação é necessário desenvolver dentre outras coisas o "[...] processo de tomada de decisão, bem como para desenvolver gerenciamento qualitativo e adequado, revelando a assimilação de novas informações e apresentando flexibilidade intelectual e adaptabilidade contextualizada no trato de situações diversas [...]".

A tomada de decisão é um ponto em comum quando se fala nas funções do administrador. Maximiano (2008) diz que quando se administra está tomando decisão e vice e versa. Pung e Hichson (2004) na obra Os Teóricos das Organizações mostra a visão de Simon, ao destacar que 
administrar é fundamental tomar decisões. E Mintzberg e Gosling (2003) considera a tomada de decisão algo essencial no papel do gestor, sendo necessária nos mais variados níveis da organização.

A Lei 4.769, de 9 de setembro de 1965, que regulamenta a profissão do administrador, vem formalizar o que os teóricos já abordavam muito tempo atrás, é possível dizer que a lei vem colocar em prática algo que na teoria já estava definido. Atividades de planejamento, coordenação, organização, controle, análise e gestão dos diversos setores de uma organização são de responsabilidade do administrador.

\subsection{Contabilidade: Suas funções e características}

O objetivo principal da contabilidade é o de permitir ao grupo principal de usuários a avaliação da situação econômica e financeira da entidade, num sentido paralisado, bem como fazer induções a respeito de tendências futuras, por meio do histórico de mudanças Marion (2007). Mesma abordagem é dada por Jiambalvo (2009) ao objetivo da contabilidade, indicando que é o de fornecer informações necessárias para o planejamento, o controle e a tomada de decisão, funções características da gestão.

Tamanha conformidade teórica é dada ao objetivo da contabilidade e, assim, as informações contábeis, que mesmo o Conselho Federal de Contabilidade (CFC) declara pela resolução $\mathrm{n}^{\circ}$ 1.374/2011, trata da nova redação dada à estrutura conceitual da contabilidade, observando que as demonstrações contábeis objetivam fornecer informações que sejam úteis na tomada de decisões econômicas e avaliações por parte dos usuários em geral, "não tendo o propósito de atender finalidade ou necessidade específica de determinados grupos de usuários" (CFC, 2011, p. 4 , grifo próprio). Isso indica que a contabilidade tem o potencial técnico e histórico de se apresentar como uma poderosa fonte de informações para subsidiar decisões de gestores, investidores, funcionários, diretores, instituições financeiras, governos, investidores ou quaisquer grupos de interessados pela organização.

Logo, reunindo tanto os posicionamentos teóricos quanto empíricos/legais, percebe-se a mesma posição na qual o objetivo da contabilidade é arrecadar dados e fornecer informações aos usuários, de forma a esclarecer a situação econômica real da entidade para, com isso, auxiliar na tomada de decisão dos administradores e demais usuários da contabilidade.
No entanto, a diversidade de usuários demandantes da informação contábil para tomada de decisão e sua consequente heterogeneidade exige uma flexibilidade no escopo e formato da informação contábil. Para Ching, Marques e Prado (2010, p. 9), a informação contábil deve possuir "utilidade e compreensibilidade como sendo atributos essenciais, uma vez que precisam ser entendidos e úteis para a tomada de decisão".

As informações contábeis, como instrumento na tomada de decisão, devem conter em seu core informativo o usuário da informação, pois é quem irá receber, decifrar e, normalmente, quem vai tomar a decisão (Iudícibus et al., 2006). Nos objetivos da contabilidade é notável a importância do usuário, tendo em vista que a informação contábil é direcionada ao usuário para auxiliar na tomada de decisão.

"Usuário" pode ser considerado aqui como qualquer pessoa (física ou jurídica) que tenha interesse em conhecer dados (normalmente fornecidos pela contabilidade) de uma entidade (Marion, 2007). Além disso, não existe somente um tipo de usuário, diversos autores, como Iudícibus et al. (2006), Marion (2007), Jiambalvo (2009) e Ching, Marques e Prado (2010) afirmam que existem outras pessoas interessadas nas informações contábeis, logo classificam os usuários em internos e externos. Isso porque esses usuários têm objetivos diferentes e, assim, apresentam necessidades informacionais diferentes (Jiambalvo, 2009).

\subsection{Controladoria: Suas funções e características}

A controladoria teve sua origem na prática, por isso não se tem uma definição muito clara sobre sua área de atuação, muitas são as pesquisas que vem sendo desenvolvidas, porém há certas divergências entre teoria e a prática (Lunkes, Schonorreberg, \& Rosa, 2013). Para Borinelli (2006), as mudanças na contabilidade gerencial fizeram com que surgisse a controladoria. A controladoria ajuda a direção e os gestores com informações que auxiliam a traçar as metas a serem seguidas e a tomar decisões baseadas nas informações recebidas.

Para Padoveze (2007) que a controladoria tem a missão de dar suporte a gestão de negócios da empresa, garantindo que ela atinja os objetivos, e alcançado esse resultado a controladoria atinge sua missão. Borinelli (2006, p.198) assegura que "a controladoria é o órgão do sistema formal da organização responsável pelo controle do processo de gestão e pela geração e fornecimento de informações de ordens operacional, econômica, 
financeira e patrimonial". Por sua vez, Mambrini, Colauto e Beuren (2004, p. 45) afirmam que "a controladoria existirá em uma empresa, quer a sua estrutura organizacional a tenha ou não como unidade administrativa".

De acordo com a visão de Mosimann e Fisch (1999, p. 88), a controladoria pode ser considerada por dois enfoques diferentes: o de unidade administrativa e como área de conhecimento, "como um órgão administrativo com missão, funções e princípios norteadores definidos no modelo de gestão do sistema empresa; e como uma área do conhecimento humano com fundamentos, conceitos, princípios e métodos oriundos de outras ciências". De acordo com Borinelli (2006, p. 114) a controladoria tem ligações com várias áreas do saber científico, essas áreas são: "contabilidade, administração, economia, direito, estatística, matemática, psicologia e sociologia”. Assim sendo fica claro que a controladoria não atua de forma fechada e isolada, é necessário se correlacionar com diversas outras áreas.

Borinelli (2006, p. 106) definiu a controladoria em três aspectos: "(a) como ramo do conhecimento, aspectos conceituais; (b) como conjuntos de atividades, funções e artefatos, aspectos procedimentais; e (c) como órgão do sistema formal organizacional das entidades, aspectos organizacionais".

$\mathrm{O}$ profissional que trabalha desenvolvendo as atividades da controladoria no Brasil é chamado de controller. Para Lunkes, Schnorrenberger e Rosa (2013) o controller pode desempenhar diversas atividades, a depender da política interna da organização, é possível ele está envolvido no planejamento, controle, sistemas de informações e contábil. Como não existe uma padronização em relação a esta função, cada organização vai procurando um perfil que mais atenda a demanda e que consiga adaptar rapidamente as mudanças.

Muitos são os questionamentos a respeito da controladoria ser uma unidade de linha ou de staff, Oliveira (2000, p. 148) comentou que unidade de "linha tem ação de comando, enquanto as unidades de organizacionais de assessoria não têm ação de comando, pois apenas aconselham as unidades de linha no desempenho de suas atividades". Padoveze (2007, p.36) afirma que a controladoria "[...] é um órgão que pode ser mais bem caracterizado como de linha, apesar de, nas funções as demais atividades internas da companhia, as características típicas serem mais de um órgão de apoio".

Segundo Padoveze (2007, p. 36) é responsabilidade da controladoria " $[. .$.$] o processo$ de assegurar a eficácia da empresa, mediante o controle das operações e seus resultados planejados". Kanitz (1976) menciona que a função da controladoria é medir e controlar a atuação das divisões da empresa.

Borinelli (2006, p. 136) em pesquisa, que foi denominada de sistematização de Estrutura Conceitual Básica da Controladoria (ECBC), buscou sistematizar o conhecimento teórico sobre controladoria, e teve como objetivo mostrar por meio de quais áreas de conhecimento a controladoria se consolida no espaço organizacional. Concluiu o seguinte:

- FUNÇÃO CONTÁBIL - compreender as atividades referentes ao desenvolvimento da contabilidade societária, como por exemplo: gerenciar as atividades de contabilidade, elaborar e analisar as demonstrações contábeis, atender as demandas informacionais do mercado e desenvolver políticas e métodos de controle;

- FUNÇÃO GERENCIAL-ESTRATÉGICA envolve a geração de informações contábil, patrimonial, econômica, financeira e não financeira necessárias para a tomada de decisão. Atividades como coordenar, assessorar e consolidar os processos de elaboração dos planos empresariais e orçamento, realizar estudos de viabilidade econômica de projetos;

- FUNÇÃO DE CUSTOS - atividades como registrar, mensurar, controlar, analisar e avaliar os custos referente a viabilidade de novos produtos e serviços, estão envolvidas nesta função;

- FUNÇÃO TRIBUTÁRIA - envolver atividades ligadas ao cumprimento das obrigações legais, e o planejamento tributaria;

- FUNÇÃ̃o DE PROTEÇÃo E CONTROLE DOS ATIVOS - registrar e controlar o patrimônio da organização;

- FUNÇÃO DE CONTROLE INTERNO estabelecer métodos de controle, para salvaguardar o patrimônio organizacional e os interesses da empresa;

- FUNÇÃO DE CONTROLE DE RISCOS identificar, medir, analisar, avaliar, divulgar e controlar os riscos envolvidos na operação;

- FUNÇÃO DE GESTÃO DA INFORMAÇÃO - criar modelos de informações e gerenciar estas informações, não sendo necessário ser apenas dados contábeis, mas podendo ser dados gerenciais. (grifo próprio)

Duque (2011) realizou uma pesquisa com o objetivo de identificar as habilidades e competências exigidas atualmente para um profissional que desempenhe o papel de controller. A formação 
requisitada no mercado de trabalho, para profissionais de controladoria, são: contabilidade e áreas afins predominando a procura, mas é possível visualizar profissionais com formação em administração, engenharia e economia.

O perfil técnico foi definido como profissionais que desempenham atividades em nível tático ou operacional e são responsáveis por fornecer informações para sua área. As tarefas mais solicitadas, de acordo com a pesquisa, foram rotinas financeiras, legislação societária, legislação tributária, rotinas fiscais e rotinas contábeis.

$\mathrm{O}$ perfil de gestão ele tem responsabilidades que envolvem a tomada de decisão, pois fornece informações e auxilia os gestores em todo o processo desta. As atividades mais solicitadas aos profissionais foram relatórios, controle, custos e orçamento.

O perfil comportamental mostra as características que são solicitadas a profissionais que atuam na área. Essas competências podem trazer vantagens competitivas aos profissionais. As principais competências citadas foram gestão de pessoas, trabalho em equipe, liderança e visão global do mercado.

Segundo a pesquisa de Duque (2011) o perfil ideal do controller é o que reúne características do perfil técnico, mais perfil de gestão e perfil comportamental.

A pesquisa realizada por Beuren, Gomes e Luz (2012) aplicada por meio de questionários enviados aos responsáveis por controladoria e diretoria, das empresas da região sudeste, abordou características como: funções/atividades desenvolvidas pela controladoria, posição ocupada pelo setor em relação ao organograma, entre outros. Analisando os dados dessa pesquisa observa-se que $56 \%$ das empresas pesquisadas tem o setor como unidade de linha, pois participa ativamente do processo de tomada de decisão. Tal pesquisa confirma resultado encontrado por Borinelli (2006, p. 268), o qual constatou que "em $73 \%$ das empresas a controladoria está ativamente envolvida no processo de tomada de decisão". E mostra que as principais funções da controladoria são: planejamento e controle do processo de gestão; gestão dos sistemas de informação; e apoio na avaliação de resultados. Como principais atividades, foi identificado: custos, orçamento e planejamento, participação na gestão, sistemas de informações.

Lunkes, Schonorrenberger e Rosa (2013) realizaram uma pesquisa a qual tinha por objetivo identificar e analisar as principais funções da controladoria, por meio de estudos empíricos e obras de referência. As informações por meio dos estudos empíricos foram levantadas da seguinte forma: primeiro, descreveu-se as funções solicitas quando as organizações fazem anúncios buscando recrutar controllers, e a segunda etapa foram as funções relatadas por meio de estudos empíricos. No campo teórico, as informações foram retiradas por meio de livros, manuais de controladoria e artigos publicados nas principais revistas nacionais. Diante disso foi possível verificar que nos estudos empíricos destacaram-se as funções relacionadas à contabilidade, controle, administração de impostos, planejamento, elaboração de relatórios e interpretação. No campo teórico, as principais funções foram as de controle, planejamento, sistema de informações e contábil.

A pesquisa de Gonçalves, Santos, Lavarda (2016) teve por objetivo evidenciar os aspectos procedimentais da estrutura conceitual básica de controladoria contemplada na gestão das indústrias do estado de Santa Catarina. Obtendo como resultado em relação à posição hierárquica, a controladoria posicionada como órgão de linha, confirmando resultados alcançados por Borinelli (2006) e Beuren, Gomes e Luz (2012), já citadas anteriormente. E destacando como principais funções: o planejamento, a elaboração, execução e controle do orçamento, as medidas corretivas e avaliação de desempenho.

\section{Procedimentos Metodológicos}

Esta seção da metodologia tem por missão descrever os procedimentos metodológicos que, sendo aplicados com rigor, diferenciam o texto acadêmico dos demais gêneros textuais (Gil, 2002; Castro, 2006).

Neste sentido, diversas tipologias são postas para classificar a pesquisa, embora não seja uma tarefa simples (Castro, 2006), em virtude do amplo uso nas ciências sociais, em especial na administração, dessa forma foi utilizada a tipologia proposta por Gil (2002), em que diferencia quanto aos objetivos da pesquisa e quanto aos procedimentos técnicos utilizados.

No que diz respeito aos objetivos da pesquisa, esta se classifica como sendo descritiva por ter como "objetivo primordial a descrição das características de determinada população ou fenômeno ou, então, o estabelecimento de relações entre variáveis" (Gil, 2002, p. 42). Quando se refere ao fenômeno, o estudo adotou o fenômeno da fama mercadológica da controladoria em meio às funções organizacionais, com destaque no que se refere à 
demanda por tal profissional diante aos profissionais contábeis e administradores. Gil (2002) conceitua ainda que quando se trata de estudar as características de um grupo, ou de grupos, este tipo de inclinação da pesquisa também se aproxima de pesquisas descritivas, como é o caso desta pesquisa em que os grupos/profissões administradores, contadores e "controllers" estão sendo analisados.

No que se refere aos procedimentos técnicos utilizados, conforme Gil (2002), em que entende serem estes procedimentos o delineamento da pesquisa, seu design ou mesmo seu planejamento, foi utilizado fundamentalmente a pesquisa bibliográfica, uma vez que neste tipo de procedimento a pesquisa se desenvolve "com base em material já elaborado, constituído principalmente de livros e artigos científicos" (Gil, 2002, p. 44).

Detalhando melhor o procedimento acima, objetivamente a pesquisa fez uma comparação entre as diversas funções da administração, contabilidade e controladoria, todas descritas na seção anterior, a fim de identificar se há sobreposição de funções.

O conjunto de obras utilizadas para evidenciar as funções, tanto de forma teórica quanto conceitual, estão descritas no quadro 1. Chama-se, a este conjunto de obras utilizadas para análise, de corpus, conforme conceituação de Bauer e Aarts (2008), deixando claro que a abordagem utilizada para tratar o material empírico foi qualitativa, com o uso da técnica de análise de conteúdo, em que as unidades de codificação foram a presença clara de uma função específica e privativa de cada profissão elencada e discutida.

Quadro 1: Obras utilizadas para a análise

\begin{tabular}{|c|c|c|c|c|}
\hline Autor(es) & Título do Texto & $\begin{array}{c}\text { Tipo: } \\
\text { Artigo; } \\
\text { Dissertação; } \\
\text { Tese; Técnico }\end{array}$ & $\begin{array}{c}\text { Meio de } \\
\text { publicação }\end{array}$ & $\begin{array}{c}\text { Ano de } \\
\text { publicação }\end{array}$ \\
\hline $\begin{array}{l}\text { Conselho Federal de } \\
\text { Administração (CFA) }\end{array}$ & Atividades Privativas & Técnico & $\begin{array}{c}\text { Divulgação } \\
\text { Oficial do CFA }\end{array}$ & $\begin{array}{l}\text { Acesso em } \\
11 / 02 / 2014 .\end{array}$ \\
\hline Ferrari, et al. & $\begin{array}{c}\text { O perfil do controller sob a } \\
\text { ótica do mercado de trabalho } \\
\text { brasileiro }\end{array}$ & Artigo & Revista & 2013 \\
\hline $\begin{array}{c}\text { Lunkes, } \\
\text { Schonorreberg, e } \\
\text { Rosa } \\
\end{array}$ & $\begin{array}{c}\text { Funções da controladoria: } \\
\text { uma análise no cenário } \\
\text { brasileiro }\end{array}$ & Artigo & Revista & 2013 \\
\hline Beuren, Gomes, e Luz & $\begin{array}{c}\text { Motivações para implantar a } \\
\text { área organizacional de } \\
\text { controladoria em grandes } \\
\text { empresas }\end{array}$ & Artigo & Revista & 2012 \\
\hline Duque & $\begin{array}{c}\text { O perfil profissional do } \\
\text { controller e as funções de } \\
\text { controladoria: um estudo da } \\
\text { atual necessidade do mercado } \\
\text { de trabalho }\end{array}$ & Dissertação & $\begin{array}{l}\text { Programa de } \\
\text { Pós-Graduação } \\
\text { [Mestrado] }\end{array}$ & 2011 \\
\hline $\begin{array}{l}\text { Ching, Marques e } \\
\text { Prado }\end{array}$ & $\begin{array}{l}\text { Contabilidade e finanças para } \\
\text { não especialistas }\end{array}$ & Técnico & Livro & 2010 \\
\hline Fayol & $\begin{array}{l}\text { Administração industrial e } \\
\text { geral: previsão, organização, } \\
\text { comando, coordenação, } \\
\text { controle }\end{array}$ & Técnico & Livro & 2009 \\
\hline Padoveze & $\begin{array}{c}\text { Controladoria estratégica e } \\
\text { operacional }\end{array}$ & Técnico & Livro & 2007 \\
\hline Chiavenato & Princípios da Administração & Técnico & Livro & 2007 \\
\hline Maximiano & Introdução à administração & Técnico & Livro & 2007 \\
\hline Marion & Contabilidade empresarial & Técnico & Livro & 2007 \\
\hline Borinelli & $\begin{array}{c}\text { Estrutura conceitual básica de } \\
\text { controladoria: sistematização } \\
\text { à luz da teoria e da práxis }\end{array}$ & Tese & $\begin{array}{c}\text { Programa de } \\
\text { Pós-Graduação } \\
\text { [Doutorado] }\end{array}$ & 2006 \\
\hline
\end{tabular}

Fonte: Elaborado pelos Autores. 
A coleta de material para compor o corpus deu-se pela busca nos sites www.spell.org.br (Scientific Periodicals Eletronic Library), desenvolvido pela Associação Nacional de Pós-Graduação e Pesquisa em Administração (ANPAD), que representa a mais elevada instituição no que tange à pesquisa e publicação em Administração no Brasil. Adicionalmente foi acessado o site www.scielo.org (Scientific Electronic Library Online), que também disponibiliza pesquisas nas ciências sociais, entre elas a administração e contabilidade.

Em ambos os sites se buscou pelos vocábulos "controladoria" e "controller", utilizou os filtros de período 2011 a 2016 e idioma Português, no Spell foi encontrado 103 resultados e na plataforma do Scielo foi encontrado 74 resultados, totalizando 177 resultados. Na sequência, procedeu-se com a leitura para verificar se os textos tratavam das funções da controladoria, de forma empírica e não apenas conceitual, procedimento que culminou em 4 artigos nesta temática.

Após os procedimentos citados acima, prosseguiu-se com um tipo de coleta conhecido como bola-de-neve, em que, para se evitar não considerar uma obra importante, recorre-se às referências dos artigos encontrados a fim de buscar alguma obra de cunho empírico que tratou das funções de controladoria, a exemplo de Cunha (2011), contemplada na pesquisa. Considerou-se, por fim, a lacuna temporal de 5 anos, mantendo textos entre os períodos de 2011 e 2016, garantindo a atualidade da discussão.

Para finalizar a construção do Corpus adicionouse 9 textos, que tanto são livros amplamente utilizados quanto matérias técnicas disponibilizadas pelos conselhos representativos das profissões, conforme consta no quadro 1.

A sequência de análise foi: (1) Leitura do resumo, a fim de identificar as funções evidenciadas pelas pesquisas; (2) Nos casos de o resumo não ter sido claro, procedeu-se com a leitura dos resultados.

O tratamento do material empírico contou com a técnica de análise de conteúdo, na forma de tabulação simples das ocorrências tendo por categorias analíticas as funções apresentadas nos diversos textos contidos no Corpus. Os resultados estão apresentados na seção a seguir.

\section{Resultados}

Admitindo os ditames da sociologia das profissões, a discussão proposta neste estudo está estruturada em quatro momentos: (1) Conhecimento estruturado, (2) código de ética, (3) Associações Profissionais e (4) Análise das funções.

\subsection{Conhecimento Estruturado}

Conhecimento estruturado, segundo a visão funcionalista da sociologia das profissões, é o conhecimento adquirido por meio de ensino e/ou treinamento técnico formal, por meio desse conhecimento desenvolve habilidades específicas e o domínio de racionalidade cognitiva, sendo atributo essencial para a distinção de uma profissão. Fica habilitado a desempenhar a ocupação os profissionais que possuem autorização, geralmente o diploma é o que atesta essa qualificação (Rodrigues, 2002: Angelin, 2010).

Na pesquisa de Duque (2011), citada no capítulo anterior, é possível visualizar que o mercado de trabalho atual busca profissionais de diversas áreas, para atuarem na função/cargo de controladoria. Predominando o profissional com formação em contabilidade e afins, seguido por administração, engenharia e economia, deixando visível que na prática não existe uma restrição para atuação de um único profissional na área. Pesquisa realizada por Ferrari et al. (2013) mostrou, como resultado, que a maior procura é por profissional de contabilidade, mas administradores e economistas, apresentam um crescente número de solicitações nos últimos anos. Informação também evidenciada na pesquisa de Calijuri (2004 apud Ferrari et al., 2013), na qual a maioria dos controllers cursou Ciências Contábeis, seguido por Administração. A mesma autora em outra pesquisa realizada por meio de anúncio de recrutamento, demostra que na maior parte das vagas para o cargo eram solicitadas formação em ciências contábeis, porém, com pouca diferença, profissionais de outras áreas também podem assumir, áreas como administração, economia ou engenharia.

Os cursos disponíveis a nível de pós-graduação (mestrado e doutorado) em controladoria apresentam relação com a administração e a contabilidade. Verificou-se esta informação por meio da consulta a base e-MEC, realizada no dia 14/04/2014, onde mostra que a nível nacional a controladoria estabelece uma inter-relação com a administração e contabilidade, pois os cursos estão sempre ligados a alguma destas áreas, não sendo um desenvolvimento específico da controladoria. Em universidades como Universidade Federal do Ceará (UFC), Universidade Federal do Amazonas (UFAM) e Universidade de São Paulo (USP), existe a oferta de mestrados acadêmicos e profissionais, bem como doutorados, 
nas áreas de "Administração e Controladoria", "Contabilidade e Controladoria" e "Controladoria e Contabilidade", simultaneamente.

A controladoria não dispõe de curso de graduação específico, uma vez que a partir de consulta a base do e-MEC, pelos termos controladoria ou controller, visualizou-se que nos casos em que aparecem cursos de graduação ou tecnólogos que envolvem tais termos estão ligados a outra área do conhecimento, em sua maioria contabilidade e administração. Considerou-se como curso de formação profissional o curso de bacharelado, e por meio das pesquisas realizadas à base do e-MEC não se encontrou nenhum curso de nível superior específico de controladoria, o que aponta para um possível entendimento de que se trata de um saber advindo de interconexões entre saberes existentes e legitimados, se aproximando a uma especialização ante a uma emergência de uma nova profissão.

Na resolução CNE/CES 10, de 16 de dezembro de 2004, o conselho de educação superior do Conselho Nacional de Educação, indica que na graduação do curso de ciências contábeis a controladoria é uma disciplina ou componente obrigatório, sendo citado como conteúdo de formação profissional. Embora o contador tenha esse amparo legal, no mercado de trabalho não é apenas tal profissão que atua na área, função ou cargo de controladoria, conforme já apresentado quando discutimos suas funções. É certo que enquanto conteúdo de formação profissional o contador está habilitado para exercer funções de controladoria, mas parece que as competências necessárias extrapolam os domínios de conhecimento do profissional contador, visto a emergência de outros profissionais nos cargos ou anúncios de controller (Duque, 2011; Lunkes, Schnorrenberger, \& Rosa, 2013).

O Conselho Federal de Contabilidade (CFC) prevê a controladoria como sendo direito ou função cativa da profissão contábil. Embora esteja realmente ligado a contabilidade, com base no Código Brasileiro de Ocupações (CBO) não existe um detalhamento das funções realizadas, conforme já foi citado neste trabalho, bem como em Fisk (1940) e Yoshitake (1982) em que já falavam da falta de definição clara das funções do controller, bem como quanto as suas responsabilidades, atribuições e compromissos. A pesquisa realizada por Lunkes et al. (2012) apresenta como resultado as funções atribuídas a controladoria, sendo elas: auditoria, administração de impostos, planejamento, controle, elaboração de relatórios e interpretação e controle interno. Porém, algumas das atividades citadas acima são responsabilidades já atribuídas a outra área ou profissão, permitindo entender que se trata de uma função a ser desempenhada na fronteira de diversos saberes, razão pela qual não se estruturou enquanto conhecimento formal no nível de bacharelado, mas se expressa mais claramente no nível de pós-graduação, relacionando-se com outros saberes, tais como administração e contabilidade, que são mais frequentes.

Assim, por este requisito ou critério definidor de profissão, que atende ao que comentam autores como Barbosa (1993), Bonelli (1993), Rodrigues (2002), Pires (2009) e Angelin (2010), não se pode entender a controladoria como uma profissão. Permite, entretanto, desenhá-la como um saber especializado, "fronteiriço", em busca de legitimidade enquanto profissão se encaminhando para um campo de disputa ante a um domínio profissional manifesto em uma profissão.

\subsection{Código de Ética}

O código de ética fixa normas que regulam profissionais de determinada classe, criando condutas cujo atendimento apontam para a moralidade dos profissionais. Outro objetivo é regular as relações entre os membros da categoria, bem como entre ela e a sociedade, de maneira impositiva. Não sendo possível optar pelo que lhe convém, mas é preciso seguir o que o código determina para a classe (Alves, 2007).

Pesquisas realizadas na plataforma do Ministério do Trabalho e Emprego, órgão que tem a responsabilidade de fornecer apoio aos trabalhadores criando novas políticas de melhorias, entende e enquadra o controller como uma subárea da contabilidade, não sendo considerada como uma área específica.

Informações obtidas em abril de 2014 na plataforma da Classificação Brasileira de Ocupações (CBO), constituída pelo Ministério do Trabalho e Emprego (MTE) que tem por objetivo identificar e classificar junto aos registros administrativos e domiciliares todas as ocupações do mercado de trabalho, indicam que controller faz parte da classe dos "contadores e afins". Isso significa dizer não tem um lócus de função próprio, o que sugere que o código de ética para os ocupantes do cargo controller possui forte vinculação com código de ética da contabilidade (ciências contábeis), ou dos profissionais da ciência contábil que figura como 
uma profissão regulamentada (Nunes \& Carvalho, 2007).

Estando enquadrado na subárea da contabilidade, faz com que o exercício da profissão do controller seja desempenhado normativamente pelo profissional contábil. Porém, na pesquisa de Duque (2011), bem como nas outras já apresentadas, encontra-se exposto de forma contundente que profissionais de área como administração, engenharia, economia e outras são procurados no mercado de trabalho para ocuparem o cargo de controller, pois o mercado tem buscado profissionais ligados a gestão e a negócios, embora predomine a procura por contador e áreas afins, mas não é apenas restrito ao contador.

Por não possuir uma área específica, também não possui o código de ética da profissão, mas fica atrelado ao código de ética do contador de forma normativa. O código de ética é entendido pela sociologia das profissões como um artefato cultural que dá identidade à profissão, pois insere-se na sociedade com uma missão, com deveres e direitos. Obviamente é uma leitura funcionalista, como o é a sociologia da profissão, mas revela que o anseio da sociedade no que diz respeito à atuação profissional demanda um comportamento específico do profissional, revelado em seu código de ética.

Neste estudo e diante das evidências apresentadas, não se considera, então, também por este critério, que o controller ou a controladoria se expressam enquanto profissão, mas como subárea da contabilidade, extrapolando suas fronteiras no que diz respeito às evidências empíricas dos profissionais que ocupam esta função ou profissão, incorporando diversos códigos de ética em virtude da pluralidade das profissões ocupantes desta função.

\subsection{Associações Profissionais}

A visão funcionalista considera as associações profissionais um mecanismo importante de manutenção e proteção das profissões. Elas têm como objetivo principal garantir a autonomia profissional e a auto regulação das profissões, em resumo, garantir o controle ocupacional (Angelin, 2010).

A pesquisa de Calijuri (2004 apud Ferrari et al., 2013) usou como base de dados controllers associados a Associação Nacional dos Executivos de Finanças (ANEFAC), mostrando que a controladoria não tem uma associação específica. Em pesquisa livre realizada no site Google, que é um site busca de uso mundial, por meio do termo "associação profissional controladoria controller" - consultado sem as aspas - o resultado não apresenta nenhuma associação específica para o profissional de controladoria. Isso reforça que a controladoria não tem uma associação específica, assim como acontece em outras áreas.

A ausência de mais um critério que define a formação de uma profissão sob o crivo da sociologia das profissões reforça as evidências já levantadas, nas quais a controladoria ainda não pode ser considerada como uma profissão, mais sim como uma subárea da contabilidade, que tem em sua ocupação no mercado diversas outras profissões, constituindo um campo plural e conflituoso, mais parecendo uma função ou domínio de saber "fronteiriço", como já foi discutido.

\subsection{Análise das Funções}

Partindo para a análise das funções, foi possível perceber que não existe uma definição clara sobre as funções desenvolvidas pela controladoria (Lunkes, Schonorreberg, \& Rosa, 2013), o fato de ter tido sua origem na prática, a exemplo a evolução da contabilidade gerencial, é apontada como uma das causas para essa ausência de definição. As funções desempenhadas por profissionais que atuam na área de controladoria também podem variar de empresa para empresa.

Ferrari et al. (2013) em sua pesquisa encontrou como principais funções solicitadas no mercado para o controller o gerenciamento da contabilidade, relatórios gerenciais, gerenciamento da tesouraria, controle fiscal e tributário, orçamento, planejamento estratégico.

Duque (2011) obteve como resultado das principais características que foram divididas em perfis técnicas, de gestão e comportamental, foram encontradas: rotinas financeiras, gerenciamento contábil, sistemas de informações, relatórios, controle, custos, orçamentos, análises financeira e contábil, planejamento e gestão de pessoas.

Lunkes, Schonorreberg e Rosa (2013), por sua vez, obtiveram como principais atividades planejamento, controle, contábil e elaboração de relatórios e interpretação após analisar as obras de Borinelli (2006), Oro et al. (2006), Daniel, Dal Vesco e Tarifa (2006), Lunkes e Schnorrenberger (2009), Chaves e Ferrari (2010) e a partir das quais puderam observar que funções relacionadas a gestão mostram que funções relacionadas a gestão contábil, relatórios gerenciais, planejamento e área tributária, 
custos e orçamentos estão presentes nos resultados de diversas pesquisas.

Gonçalves, Santos e Lavarda (2016), principais atividades foram: planejamento, elaboração, execução e controle do orçamento, medidas corretivas e avaliação de desempenho.

Como já citado nesse trabalho, profissionais da área de contabilidade, administração, engenharia e economia estão na lista dos profissionais que tem sido solicitado pelo mercado de trabalho para atuarem como controller e sendo confirmado nas pesquisas de Duque (2011) e Ferrari et al. (2013), embora o CBO indique que a controladoria é uma área (ocupação) da família da contabilidade, mas o mercado tem solicitado profissionais também de outras áreas.
Em resumo pode-se fazer o seguinte desenho das funções da administração, contabilidade e controladoria, levantadas nessa pesquisa (figura 1).

A administração com a função de tomar decisões que impactam no futuro da organização, quando planeja, controla, organiza e dirige, está focando em obter maior resultado (eficiência e eficácia). A contabilidade tem como objetivo principal, fornecer informações importantes para o processo de tomada de decisão, e a seu turno, a controladoria com funções de rotinas financeiras, gerenciamento contábil, sistemas de informações, relatórios, controle, custos, orçamentos, análise financeira e contábil, planejamento e gestão de pessoas.

Figura 1: Atividades por função

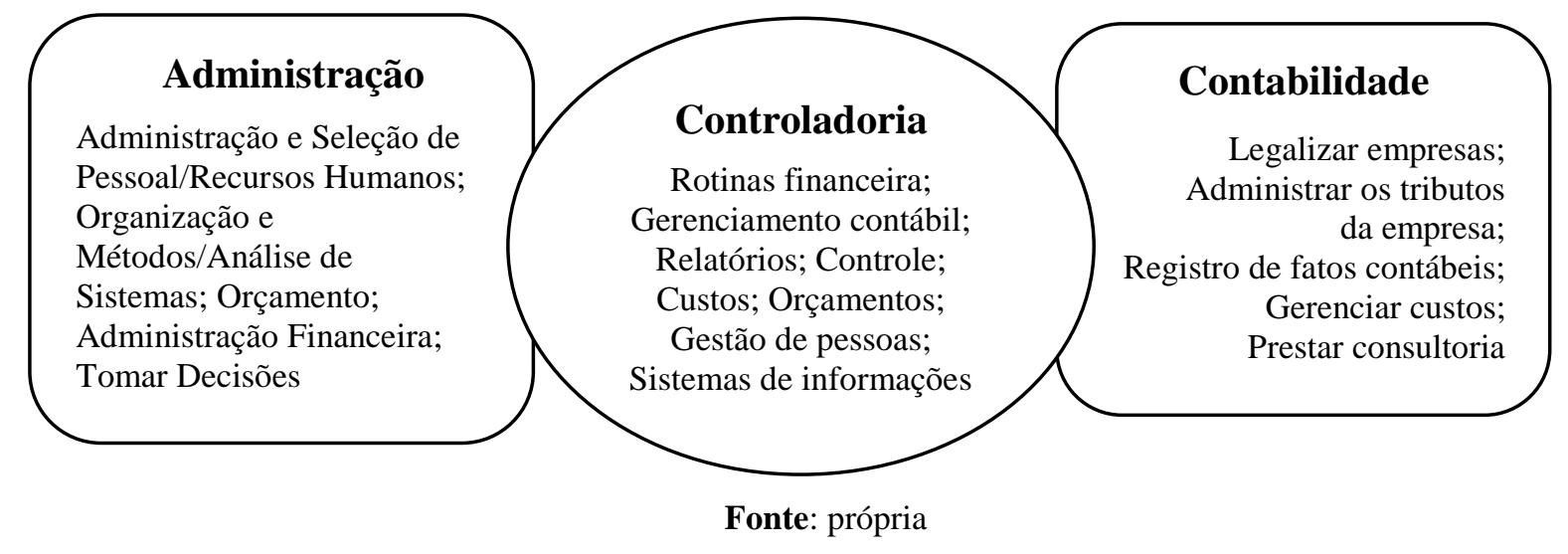

De acordo com os dados levantados no quadro anterior, é possível visualizar que a controladoria "ultrapassa" os limites da contabilidade, que segundo Jiambalvo (2009) tem o objetivo de fornecer informações necessárias para o planejamento, o controle e a tomada de decisão, funções características da gestão, além de ter adentrado em áreas que são privativas da administração, que por sua vez tem a responsabilidades de tomar decisões com impactos holísticos na organização e que terá repercussão no futuro da organização.

Isso pode ser causado por ser um cargo ocupado por profissionais de diversas áreas, embora formalmente o CBO seja da área da contabilidade, e também pelo fato de não ter definido o rol das suas funções, de forma que a deixa "solta".

Conforme foi visto por diversos autores, como
Borinelli (2006), Padoveze (2007), Duque (2011), Beuren, Gomes, Luz (2012), Gonçalves, Santos, e Lavarda (2016), a controladoria encontra-se enquadrada como um órgão de linha, pois participa ativamente do processo de tomada de decisão, porém pesquisa como a desenvolvida por Cavalcante et al. (2012) obteve como resultado que em $74,4 \%$ das empresas pesquisadas a controladoria esta enquadrada como órgão de staff, apenas assessorando decisões.

Sendo assim, pelo que perece evidenciado nas pesquisas, não há consenso quanto à atuação na estrutura (linha ou staff) tampouco quanto às funções. Esse resultado indica que, além de não atender aos critérios da sociologia das profissões quanto à classificação, o atual estado do entendimento da controladoria aponta para um campo em disputa, sobretudo pelo domínio profissional. É certo que normativamente é cativo 
aos profissionais contábeis (ciências contábeis) o exercício da profissão de controller, no entanto às demandas de mercado e, muito além disso, as funções desempenhadas extrapolam o escopo da contabilidade.

A título de exemplo, uma vez que já foi indicado sumariamente as funções em resumo na figura 1 , uma função é icônica no que diz respeito a relação entre a controladoria, a contabilidade e a administração, que é a função "gestão de pessoas" que envolve seleção, alocação, coordenação, controle, desenvolvimento e cargos/salário dos colaboradores, é uma função privativa do administrador, porém encontra-se nas funções do controller. É muito importante para a tomada de decisão com impacto holístico na organização, que a gestão de pessoas funcione de forma eficiente e eficaz, para que otimize os resultados e não os comprometam. Isso mostra que há, de certo modo, um avanço no campo profissional do administrador.

Do lado da contabilidade, é flagrante que quando indica "gerenciamento contábil" como função subjuga a contabilidade à controladoria, indicando que não é uma subárea, mas sim uma concepção de pertença, na qual a contabilidade pertence à controladoria e não esta àquela. Pois, conforme já citado a controladoria normativamente esta como uma subárea da contabilidade, porém ela tendo a função de gerenciamento, ela passar a ser responsável e responder pela contabilidade, quando na verdade a controladoria, que seguindo a normativa precisa responder a contabilidade.

\section{Considerações Finais}

Esse estudo teve como objetivo discutir como a controladoria se relaciona com a Contabilidade e Administração: Uma nova profissão ou uma especialização?, contribuindo como conhecimento no que diz respeito às formas de expressão de cada saber, para que possa entender os "limites" de atuação para cada "profissional". Julga-se, portanto, atingido tal objetivo já que se debateu as funções privativas do administrador contador e controller. Usou como base a sociologia das profissões, e visualizou os elementos essenciais pra ser considerado uma profissão e não apenas uma ocupação. Diante isso foi possível visualizar que o mercado de trabalho pode demandar um profissional, mesmo sem ele ter uma área específica e sem ter um conhecimento estruturado (bacharelado e/ou técnico).

A ausência de um rol de funções e de uma área de atuação para a controladoria, tem causado uma certa "disputa" de funções envolvendo a contabilidade, administração e controladoria, sem contar as outras profissões que exercem empiricamente esta função, porém em menor número. Embora o controller seja normativamente regulamentado pela profissão contábil, a ausência de um conhecimento para tal área faz com que o mercado de trabalho busque por profissionais de diversas profissões. Pode-se, então, afirmar que isso dificulta ainda mais a "limitação" de atuação, permitindo que o controller atue de forma "solta" sem recorrer a uma profissão nem tampouco a nenhum conhecimento estruturado.

A controladoria na prática tem ultrapassado os limites da contabilidade e adentrado os limites da administração, atuando com funções que são privativas desta. Resultados de pesquisas onde apontam que a controladoria aumentou a eficiência e eficácia da organização, pode comprovar a "invasão" dentro da área administrativa, pois Taylor defende que o administrador precisa ser eficiente e eficaz para que possa assegurar o crescimento da empresa.

A tomada de decisão que impactam no futuro da organização é algo próprio do administrador e fornecer informações úteis para a tomada de decisão é papel do contador, porém entre eles não esta existindo essa "conversa" e faz com que o controller tenha espaço nesse meio, em alguns casos chegando a participar diretamente das decisões e, em outros casos, sendo responsável pela contabilidade.

Deste modo, a relevância deste estudo surge desta evidência, de entender que o controller está desempenhando papéis tanto do administrador quanto do contador, sendo função privativa deste último mas ultrapassando suas funções e, no que compete ao administrador, vê que várias funções que lhe dão identidade estão sendo desempenhadas por outros profissional.

Assim, figura-se por conclusão provisória - como são todas na ciência - que a controladoria é um campo em disputa envolvendo prioritariamente a administração e a contabilidade, e a importância desta revelação é que estas profissões devem preocupar-se com suas identidades, que se manifestam num conjunto estruturado de saber (conhecimento), código de ética e associação profissional, legitimando o saber e permitindo o exercício profissional vinculado à uma demanda social, técnica e política.

É certo que a emergência de uma profissão se dá em meio à outra(s), porém, qual profissão dará espaço para o surgimento da controladoria ainda está em processo, pois envolve, além de legitimidade social, poder político. Entender este processo é dar 
passos largos na compreensão do futuro profissional daqueles envolvidos.

\section{Referências}

Alves, F. J. S., Lisboa, N. P., \& Weffort, E. F. J., Antunes, M.T.P. (2007). Um estudo empírico sobre a importância do código de ética profissional para o contabilista. Revista Contabilidade \& Finanças, Ed. Esp. (30 anos de doutorado), p. 58-68, jun.

Angelin, E. P. (2010). Profissionalismo e profissão: Teorias sociológicas e o processo de profissionalização no Brasil. Revista Espaço de Diálogo e Desconexão, v. 3, n.1, Jul./Dez.

Bauer, M. W.; Aarts, B. A. (2008). Construção do Corpus: Um princípio para a coleta de dados qualitativos. In: BAUER; M. W.; GASKELL, G. Pesquisa qualitativa com texto, imagem e som: Uma manual prático. 7 ed. Petrópolis (RJ): Vozes, p. 39-63.

Beuren, M. I, Gomes, E.C.O, \& Luz, R. M. (2012). Motivações para implantar a área organizacional de controladoria em grandes empresas. Revista Gestão e Regionalidade, v.28, n 82, Jan./Abr.

Borinelli, M. L. (2006). Estrutura conceitual básica da controladoria: sistematização à luz da teoria e da práxis. Tese (doutorado em Ciências Contábeis) - Universidade de São Paulo - USP, São Paulo.

Castro, C. M. (2006). A prática da pesquisa. 2 ed. São Paulo: Pearson Prentice Hall.

Cavalcante, D. S., De Luca, M. M. M., Ponte, V. M. R, \& Gallon, A. V. (2012). Características da Controladoria nas maiores companhias listadas na BM\&FBOVESPA. Revista Universo Contábil, v. 8, n. 3, p. 113-134, jul./set.

Chiavenato, I. (2006). Princípios de administração: o essencial em teoria geral da administração. Rio de Janeiro: Elsevier.

Ching, H. Y., Marques, F., \& Prado, L. (2010). Contabilidade e finanças para não especialistas. 3 ed. São Paulo: Pearson Prentice.

Conselho Federal de Contabilidade (CFC). Resolução $C F C n^{\circ} 1.374 / 11$. Dá nova redação à NBC TG Estrutura Conceitual - Estrutura Conceitual para elaboração e divulgação de relatório contábil-financeiro. Diário Oficial da União, Brasília, 8 Dez, 2011.

Duque, C. (2011). O perfil profissional do controller e as funções de controladoria: um estudo atual necessidade do mercado de trabalho. Dissertação (mestrado em Ciências Contábeis) -

Universidade Federal de Pernambuco, Recife.

Fayol, H. (2009). Administração industrial e geral: previsão, organização, comando, coordenação, controle. 10. ed. São Paulo: Atlas.

Fernandes, F. C., Klann, R. C., \& Figueredo, M. S. (2011). A utilidade da informação contábil para a tomada de decisões: Uma pesquisa com gestores alunos. Revista Contabilidade Vista \& Revista, v. 23, n. 3, p. 99-126, Jul./Set., 2011.

Ferrari, M. J., Cunha, L.C., Lunkes, R.J., \& Borget, A. (2013). O perfil do controller sob a ótica do mercado de trabalho brasileiro. Revista de Informação Contábil. Vol. $7^{\circ}$, p. 25-50, Jul-Set.

Foucault, M. (2008). A Arqueologia do Saber. 7 ed. Rio de Janeiro: Forense Universitária.

Francia, A. J., Porter, M. C., Strawser, R. H, \& Strawser, J. R. (1999). Managerial accounting. 9. ed. Houstom: Dame Publ.

Gil, A. C. (2002). Como elaborar projetos de pesquisa. 4 ed. São Paulo: Atlas.

Gonçalves, M., Santos, C. A., \& Lavarda, C. E. F. (2016). Estudo dos aspectos procedimentais da estrutura conceitual básica de controladoria na gestão das indústrias do estado de Santa Catarina. Pensar Contábil. V.18, n. 65 p. 4-15, Jan-Abr.

Iudícibus, S., Kanitz, S., Martins, E., Chinen, C. A. K., Castilho, E., \& Lisboa, L. P. (2006). Contabilidade introdutória. 10. ed. São Paulo: Atlas.

Jiambalvo, J. (2009). Contabilidade gerencial. Rio de Janeiro: LTC.

Kanitz, S. C. (1976). Controladoria: teoria e estudos de caso. São Paulo: Pioneira.

Lunkes, J. R, Schnorrenberger, D, \& Rosa, F.S. (2013). Funções da controladoria: uma análise no cenário brasileiro. Revista Brasileira de Gestão de Negócios. v.15. São Paulo.

Lunkes, J. R. et al. (2012) Análise da legitimidade sociopolítica e cognitiva da controladoria no Brasil. Revista Contabilidade Financeira - USP v.23. São Paulo, 2012.

Mambrini, A., Colauto, R. D., \& Beuren, I. M. (2004). Papel da controladoria no redesenho da gestão na perspectiva dos processos em empresa familiar. Revista Enfoque Reflexão Contábil. v.23, n.2, p.5-13, julho/dezembro.

Marion, J. C. (2007). Contabilidade empresarial. 13 
ed. São Paulo: Atlas.

Maximiano, A. C. A. (2008). Introdução à administração. São Paulo: Atlas.

Mintzberg, H., \& Gosling, J. (2003). Educando administradores além das fronteiras. Revista de Administração de Empresas (RAE). v. 43, n. 2, Abr/Mai/Jun.

Mosimann, C.P., \& Fisch, S. (1999). Controladoria. 2. ed. São Paulo: Atlas.

Motta, F. C. P. (2003). Teoria das organizações: evolução e crítica. 2. ed. rev. e ampl. São Paulo: Pioneira Thomson Learnin.

Nunes, E., \& Carvalho, M. M. (2007). Ensino Universitário, Corporação e Profissão: Paradoxos e dilemas brasileiros. Sociologias. Ano 9, n. 17, p. 190-215, mai./jun.

Oliveira, D. P. R. de. (2000). Sistemas, organização e métodos: uma abordagem gerencial. 11. ed. São Paulo: Atlas.

Padoveze, C. L. (2007). Controladoria estratégica e operacional: conceitos, estrutura, aplicação. São
Paulo: Thomson Learning.

Pires, D. (2009). A enfermagem enquanto disciplina, profissão e trabalho. Revista Brasileira de Enfermagem. p. 739-744, setembro/outubro.

Pung, D. S., \& Hickson, D. J. (2004). Os teóricos das organizações. Organizadores. Rio de Janeiro: Qualitymark.

Rodrigues, F. X. F. (2002) A sociologia das profissões e a sociologia do esporte:

Profissionalização e mercado de trabalho no futebol Gaúcho. Disponível em:

<http://portal.anpocs.org/portal/index.php?option $=$ com_docman $\&$ task $=$ doc_view $\&$ gid $=4376 \&$ Ite mid=317 . . Acesso em: 13 jun. 2014.

Santos, A. F. (2011). A importância da disciplina contabilidade e planejamento tributário no curso de administração. In: Seminários em Administração (SEMEAD). XIV, 13-14 Out., São Paulo (SP).

Taylor, F. W. (2008). Princípios da administração científica. 6. ed. São Paulo: Atlas.

\title{
The relationship between Controllership and Management: Specialization or invasion of field?
}

\begin{abstract}
Faced with the empirical distance observed between administrators and accountants, several areas have arisen, one of which is the controller. Based on this evidence, the objective of this study is to discuss whether a controlling profession figures as a new profession or an advance in Administration and / or Accounting specialization, with secondary objectives defining and summarizing the functions of administration, accounting and controlling. To that end, a review was made of the functions of each area, trying to understand the limits of each professional and what are the essential elements for the formation of a profession, according to the functionalist view of the theory of professions. A corpus was set up, to show the functions, from scientific articles published in the period from 2011 to 2016, in Spell and Scielo sites, dissertation, thesis and books. It was considered the texts dealing with the functions of the controller, in an empirical way and not only conceptual. The result showed that, according to the functionalist view of the sociology of professions, the controller does not yet qualify as a profession, due to the absence of essential elements such as structured knowledge, code of ethics and professional associations. It was also seen that it goes beyond the limits of accounting, and enters the administration area, this is due to the lack of consensus regarding its functions and area of activity. In this sense, this study contributes to the understanding of the functions of the administration and its connection with emerging knowledge, specifically control.
\end{abstract}

Keywords: Management; Controllership; Accounting. 


\section{La relación entre la Gestión de Control y la Administración: ¿especialización o invasión del área?}

\section{Resumen:}

Ante el distanciamiento empírico observado entre los administradores y contadores, ha surgido varias áreas, una de ellas es la Gestión de Control. Basado en esta evidencia, el objetivo de este estudio es discutir si la misma se figura como una nueva profesión o un avance en especialización de la Administración y/o de la Contabilidad, teniendo por objetivos secundarios definir y resumir las funciones de la Administración, de la Contabilidad y de la Gestión de Control. Para eso, se realizó una revisión acerca de las funciones de cada área, tratando de entender los límites de cada profesional y cuáles son los elementos esenciales para la formación de una profesión, de acuerdo con la visión funcionalista de la teoría de las profesiones. Se ha configurado un corpus, para evidenciar las funciones, a partir de artículos científicos publicados en el período de 2011 a 2016, en los sitios Spell y Scielo, y otras publicaciones académicas. Se consideró los textos que trataban de las funciones de la Gestión de Control de forma empírica y no sólo conceptual. El resultado comprueba que según la visión funcionalista de la sociología de las profesiones, la Gestión de Control no se adecua aún como profesión, por ausencia de elementos esenciales, tales como: conocimiento estructurado, código de ética y asociaciones profesionales. El estudio señala también que ese proceso administrativo extrapola el límite de la Contabilidad, y adentra en el área de la Administración, eso sucede por la falta de consenso en cuanto a sus funciones y área de actuación. En este sentido, este estudio contribuye a la comprensión de las funciones de la Administración y su vinculación con saberes emergentes, específicamente la Gestión de Control.

Palabras Clave: Administración; Gestión de Control; Contabilidad.

\section{Sobre os Autores}

\section{Jéssica Santos de ASSUNÇÃO}

Graduado em Administração pela Faculdade de Ciências da Administração de Garanhuns (FAGA/AESGA) Avenida Caruaru, 508 - São José - Garanhuns - PE - Brasil - CEP 55.595-380

E-mail: jessicasantos.a@hotmail.com

\section{Aécio Cristóvão Pereira de MELO}

Graduado em Administração pela Faculdade de Ciências da Administração de Garanhuns (FAGA/AESGA)

Avenida Caruaru, 508 - São José - Garanhuns - PE - Brasil - CEP 55.595-380

E-mail: aecio.cristovao@gmail.com

\section{Gabriela Fernanda Alcântara Valença PAIVA}

Mestra em Gestão de Políticas Públicas pela Fundação Joaquim Nabuco (FUNDAJ). Professora das Faculdades Integradas de Garanhuns (FACIGA).

Avenida Caruaru, 508 - São José - Garanhuns - PE - Brasil - CEP 55.595-380

E-mail: gabrielavalenca@ hotmail.com 